\title{
David Versus the Goliaths for the Detection of Bone Metastases
}

\author{
Gary A. Ulaner \\ Department of Radiology, Memorial Sloan Kettering Cancer Center, New York
}

See the associated article on page 1778.

would be easy to presume that advanced hybrid imaging modalities, such as PET/CT and PET/MR, would produce more clinically valuable information than older techniques such as bone scintigraphy. The advantage of multiplanar reconstructions over planar imaging (1), the higher resolution of PET than SPECT $(2,3)$, and the anatomic correlation provided by the addition of CT or MR $(4,5)$ make the battle between bone scintigraphy (David) and PET/CT or PET/MR (the Goliaths) appear unequal. Indeed, multiple previous studies have concluded that the Goliaths handily defeat David (6-11).

This is what makes the report by Löfgren et al. (12) remarkable. Löfgren et al. expertly perform a prospective trial comparing the ability of David versus the Goliaths to detect bone metastases in a cohort of patients with known malignancy and clinical suspicion for bone metastases, and find no difference between them. The use of a modality including CT or MR did increase the confidence of reader interpretation, thus reducing equivocal reads, but the authors conclude that there was little improvement in the detection of osseous malignancy when using PET/CT or PET/MR compared with bone scintigraphy. This report challenges the presumption that the use of advanced imaging modalities will result in greater clinical value.

There are notable limitations to the study. First, there was histologic proof of suggestive imaging findings in only 2 patients. In 1 of these 2 patients, the suggestive imaging finding was histologically evaluated after a partial resection of a rib lesion, and the histology turned out to be benign. Thus, for most patients, the reference standard for the presence of malignancy used the imaging findings in determining the reference standard. This could result in circular logic, that is, the imaging findings are used to determine the reference standard of metastases, and the reference standard of metastases is then used as evidence that the imaging findings are correct. Having a reference standard, such as histology, that is independent of the imaging findings would provide much stronger evidence. Of course, there are logistical and ethical difficulties in designing a study in which all patients have histologic proof of their imaging findings. This is a

Received Aug. 9, 2017; revision accepted Aug. 10, 2017.

For correspondence or reprints contact: Gary A. Ulaner, Memorial Sloan Kettering Cancer Center, 1275 York Ave., Box 77, New York, NY 10065.

E-mail: ulanerg@mskcc.org

Published online Aug. 17, 2017.

COPYRIGHT (C) 2017 by the Society of Nuclear Medicine and Molecular Imaging. DOI: 10.2967/jnumed.117.199893 conundrum that introduces limitations in many studies. However, it should be recognized that the reference standard used in this study may be suboptimal.

Second, as the authors admit, the study is underpowered. The power of a study is the probability of rejecting the null hypothesis when the null hypothesis is false (13). In this study, the null hypothesis is that the ability of bone scintigraphy to detect the presence of osseous metastases is equal to that of the advanced imaging modalities. If we reject the null hypothesis, then we assert that one method is superior to the other. A study should have sufficient statistical power to reduce the chance of concluding that the null hypothesis is correct when it is actually false. This would result in a false-negative study, also known as a type II error (13). Power is best calculated prospectively. For this study, power was prospectively calculated by assuming that $30 \%$ of patients would have osseous metastases. For a power of $80 \%$ and an $\alpha$ (type I error rate) of $5 \%$, the sample size calculation was determined to be 120 patients. With a power of $80 \%$, there would be only a $20 \%$ chance of a false-negative study. However, in actuality, only 16 of $117(14 \%)$ patients were determined to have osseous metastases during the study. Given this small proportion, the number of patients needed for $80 \%$ power would need to be much higher than 120 . If the power of the study is too low, then it increases the chance of the study failing to detect a difference when one truly exists, and thus it may not be accurate to conclude there is no difference between the modalities. There may truly be a difference between the modalities, but the study did not detect it. It is normally not appropriate to determine the power of a study retrospectively; however, this may be done in certain circumstances (14). It would be interesting to determine the power of this study based on the actual patient characteristics. Clinicaltrials.gov contains a study of ${ }^{18} \mathrm{~F}-\mathrm{NaF}$ PET/CT versus ${ }^{99 \mathrm{~m}} \mathrm{Tc}-\mathrm{C}$-thylene diphosphonate bone scintigraphy for the detection of osseous metastases (NCT00882609) for which the completion date has passed, though the study's results have not yet been published. This study is designed to determine whether ${ }^{18} \mathrm{~F}-\mathrm{NaF}$ PET/CT leads to improved treatment and patient outcomes compared with bone scintigraphy. It should have greater statistical power than the study by Löfgren et al., and the results will be of great interest when published.

So what can we glean from Löfgren et al.? In a population for which the likelihood of osseous metastases is relatively low, bone scintigraphy may perform equally well compared with more advanced imaging modalities for the detection of the presence of osseous metastases. This is good news for bone scintigraphy. Given the low cost and widespread availability of bone scintigraphy (15), Löfgren et al. could breathe new life into this nuclear medicine standard during an era when the most advanced imaging possible is increasingly used. Clearly, when determining the value of an imaging study, it is not just the technical aspects of the 
imaging modality, but also the intended patient population, that will help determine the optimal imaging method. For some patient populations, David may be equally strong as the Goliaths.

\section{DISCLOSURE}

No potential conflict of interest relevant to this article was reported.

\section{REFERENCES}

1. Sarikaya I, Sarikaya A, Holder LE. The role of single photon emission computed tomography in bone imaging. Semin Nucl Med. 2001;31:3-16.

2. Cook GJ, Fogelman I. The role of positron emission tomography in the management of bone metastases. Cancer. 2000;88:2927-2933.

3. Segall G, Delbeke D, Stabin MG, et al. SNM practice guideline for sodium ${ }^{18}$ F-fluoride PET/CT bone scans 1.0. J Nucl Med. 2010;51:1813-1820.

4. Townsend DW. Dual-modality imaging: combining anatomy and function. $J$ Nucl Med. 2008;49:938-955.

5. Helyar V, Mohan HK, Barwick T, et al. The added value of multislice SPECT/CT in patients with equivocal bony metastasis from carcinoma of the prostate. Eur $J$ Nucl Med Mol Imaging. 2010;37:706-713.

6. Schirrmeister H, Guhlmann A, Elsner K, et al. Sensitivity in detecting osseous lesions depends on anatomic localization: planar bone scintigraphy versus ${ }^{18}$ F PET. J Nucl Med. 1999;40:1623-1629.
7. Langsteger W, Heinisch M, Fogelman I. The role of fluorodeoxyglucose, ${ }^{18} \mathrm{~F}$-dihydroxyphenylalanine, ${ }^{18} \mathrm{~F}$-choline, and ${ }^{18} \mathrm{~F}$-fluoride in bone imaging with emphasis on prostate and breast. Semin Nucl Med. 2006;36:73-92.

8. Apolo AB, Lindenberg L, Shih $\mathrm{JH}$, et al. Prospective study evaluating $\mathrm{Na}^{18} \mathrm{~F}$ $\mathrm{PET} / \mathrm{CT}$ in predicting clinical outcomes and survival in advanced prostate cancer. J Nucl Med. 2016;57:886-892.

9. Minamimoto R, Loening A, Jamali M, et al. Prospective comparison of ${ }^{99 \mathrm{~m} T c-M D P}$ scintigraphy, combined ${ }^{18} \mathrm{~F}-\mathrm{NaF}$ and ${ }^{18} \mathrm{~F}-\mathrm{FDG}$ PET/CT, and whole-body MRI in patients with breast and prostate cancer. $J$ Nucl Med. 2015;56:1862-1868.

10. Tateishi U, Morita S, Taguri M, et al. A meta-analysis of ${ }^{18} \mathrm{~F}$-Fluoride positron emission tomography for assessment of metastatic bone tumor. Ann Nucl Med. 2010;24:523-531.

11. Shen CT, Qiu ZL, Han TT, Luo QY. Performance of ${ }^{18} \mathrm{~F}$-fluoride PET or PET/CT for the detection of bone metastases: a meta-analysis. Clin Nucl Med. 2015;40:103-110.

12. Löfgren J, Mortensen J, Rasmussen SH, et al. A prospective study comparing ${ }^{99 m} \mathrm{Tc}$-hydroxyethylene-diphosphonate planar bone scintigraphy and whole-body SPECT/CT with ${ }^{18} \mathrm{~F}$-fluoride PET/CT and ${ }^{18} \mathrm{~F}$-fluoride PET/MRI for diagnosing bone metastases. J Nucl Med. 2017;58:1778-1785.

13. Williams JL, Hathaway CA, Kloster KL, Layne BH. Low power, type II errors, and other statistical problems in recent cardiovascular research. Am J Physiol. 1997;273:H487-H493.

14. Hogarty KY, Kromrey JD. RETR_PWR: an SAS macro for retrospective statistical power analysis. Behav Res Methods Instrum Comput. 2003;35: $585-589$.

15. Love C, Din AS, Tomas MB, Kalapparambath TP, Palestro CJ. Radionuclide bone imaging: an illustrative review. Radiographics. 2003;23:341-358. 